(2) Open Access Full Text Article

\title{
latrogenic retinal breaks during 20-gauge vitrectomy for proliferative diabetic retinopathy
}

This article was published in the following Dove Press journal:

Clinical Ophthalmology

27 December 2012

Number of times this article has been viewed

\section{Yumi Kamura' \\ Yukihiro Sato ${ }^{2}$ \\ Yuzou Deguchi ${ }^{3}$ \\ Fumihiko Yagi ${ }^{3}$ \\ 'Department of Ophthalmology, Division of Visual Sciences, Nihon University School of Medicine, Tokyo, Japan; ${ }^{2}$ Department of Diabetes Center, Jichi Medical University, Tochigi, Japan; ${ }^{3}$ Department of Ophthalmology, Toho University Sakura Medical Center, Chiba, Japan}

Correspondence:Yumi Kamura Department of Ophthalmology, Division of Visual Sciences, Nihon University School of Medicine, 30-I Ohyaguchi kamimachi, Itabashi-ku,Tokyo, |73-86|0, Japan

$\mathrm{Tel}+8$ I 339728 III ext 253।

Fax +81359953495

Email kamura.yumi@nihon-u.ac.jp
Background: We classified iatrogenic retinal break formation during 20-gauge pars plana vitrectomy for proliferative diabetic retinopathy into three types according to the mechanism of development, and evaluated the association of each type with postoperative complications. This is the largest series of such patients published to date.

Methods: This was a retrospective comparative study of 760 eyes from 609 cases who underwent primary 20-gauge vitrectomy for proliferative diabetic retinopathy and were followed-up for at least 6 months after surgery. Postoperatively, the eyes were classified as having vitreous hemorrhage only (group 1), fibrovascular membrane without traction retinal detachment (group 2), or fibrovascular membrane with traction retinal detachment (group 3).

Results: The overall incidence of iatrogenic retinal breaks was $29 \%$. Fibrovascular membrane dissection was associated with retinal break formation in 50 of the eyes in group 3, an incidence which was significantly higher than that in group $2(P<0.001)$. Posterior vitreous detachment creation and peripheral vitreous shaving were associated with retinal break formation in $8 \%$ of eyes overall, and oral dialysis occurred in $2 \%$. Postoperatively, vitreous hemorrhage requiring washout, neovascular glaucoma, recurrent retinal detachments, and fibrovascular proliferation at the sclerotomy sites occurred in $4 \%, 4 \%, 3 \%$, and $1 \%$, respectively, of all eyes. Outcomes of eyes with these postoperative complications, other than vitreous hemorrhage, were poor. Multiple regression analysis revealed retinal break formation during fibrovascular membrane dissection to be significantly related to postoperative vitreous hemorrhage $(P=0.019)$, recurrent retinal detachments $(P<0.001)$, and neovascular glaucoma $(P=0.048)$. Oral dialysis was also significantly related to postoperative vitreous hemorrhage $(P=0.001)$.

Conclusion: Iatrogenic retinal break formation during fibrovascular membrane dissection was more likely to be the cause of poor outcomes than peripheral retinal breaks or oral dialysis.

Keywords: iatrogenic retinal breaks, 20-gauge vitrectomy, proliferative diabetic retinopathy, postoperative complications

\section{Introduction}

Vitreous surgery for proliferative diabetic retinopathy has been reported to be closely associated with severe intraoperative and postoperative complications. ${ }^{1}$ Iatrogenic breaks develop via different mechanisms, such as oral dialysis and during proliferative fibrovascular membrane dissection. ${ }^{2}$ To our knowledge, there has been only one previous study in which iatrogenic retinal breaks were classified according to mechanisms of development. ${ }^{2}$ In that study, breaks were divided into two groups, ie, posterior breaks and peripheral breaks, to allow incidence comparisons between 20-gauge and 23-gauge vitrectomy for proliferative diabetic retinopathy. In our study, iatrogenic breaks were classified into three types, ie, breaks occurring during fibrovascular membrane dissection, 
those occurring during the induction of posterior vitreous detachment or peripheral vitreous dissection, and oral dialysis related to the sclerotomy sites. Their incidences and associations with major postoperative complications were evaluated in the largest published series to date of patients undergoing 20-gauge vitrectomy for proliferative diabetic retinopathy. These evaluations may provide basic data allowing comparison between 20 -gauge vitrectomy and micro-incision vitreous surgery for proliferative diabetic retinopathy.

\section{Materials and methods}

The subjects consisted of 609 consecutive patients ( 760 eyes) who underwent their first operation for proliferative diabetic retinopathy between August 2001 and September 2003 at Nihon University Itabashi Hospital and between October 2003 and March 2008 at Sakura Medical Center Toho University Hospital. All were followed up for at least 6 months after their surgery. There were 385 males and 224 females of mean age $57.3 \pm 11.4$ (range $24-84$ ) years.

Vitreous surgery was performed using a 20-gauge threeport vitrectomy system. When there was no posterior vitreous detachment, it was induced. Proliferative membrane dissection using vertical or horizontal scissors and intraocular photocoagulation were performed, and intraocular tamponade was added when necessary. In phakic patients aged $\geq 50$ years, cataract surgery was simultaneously performed. The operations were performed by 15 surgeons.

Patients with neovascular glaucoma before surgery, those who underwent surgery to treat macular edema or to remove submacular hard exudates, and those with pre-existing retinal breaks including combined traction and rhegmatogenous retinal detachment were excluded. No patients were treated with bevacizumab (antivascular endothelial growth factor) either preoperatively or postoperatively.

The subjects were classified postoperatively according to their disease type into three groups, ie, group 1 with vitreous hemorrhage only, group 2 with fibrovascular membranes requiring treatment without traction retinal detachment, and group 3 with fibrovascular membrane and traction retinal detachments.

Iatrogenic breaks were classified into breaks occurring during fibrovascular membrane dissection (breaks during membrane dissection), breaks occurring during the induction of posterior vitreous detachment or peripheral vitreous dissection (peripheral breaks), and oral dialysis related to the sclerotomy sites.

The postoperative complications evaluated were vitreous rebleeding requiring washout on reoperation (rebleeding), neovascularization at the sclerotomy site, retinal detachment due to reproliferation with or without retinal breaks, and neovascular glaucoma. This retrospective study was performed using medical records. Visual acuities were measured using a standard Japanese decimal visual acuity chart.

\section{Statistical analysis}

The $\chi^{2}$ test, $m x n \chi^{2}$ test, Fisher's exact probability test, logistic regression analysis, and multiple comparisons with the Bonferroni method were used to perform the statistical analysis. $P<0.05$ was regarded as being statistically significant. StatView 5.0 (SAS Institute Inc, Cary, NC, USA) was the statistical analysis software package used.

\section{Results \\ Patients}

Group 1 consisted of 239 patients (259 eyes), group 2 consisted of 286 patients ( 318 eyes), and group 3 of 161 patients (183 eyes). The mean ages of the patient were $60.0 \pm 10.9$, $56.2 \pm 11.0$, and $53.6 \pm 12.0$ years, respectively.

\section{Incidence of iatrogenic breaks}

\section{All cases}

Iatrogenic breaks occurred in $28.5 \%$ of all 760 eyes. Breaks during membrane dissection developed in $31.5 \%$ of eyes in groups 2 and 3 after membrane dissection. Peripheral breaks occurred in $7.5 \%$ and oral dialysis in $2.1 \%$ of all eyes.

\section{According to group}

Iatrogenic breaks occurred in $8.9 \%, 29.2 \%$, and $62.8 \%$ of groups 1, 2, and 3, respectively (see Table 1). Breaks during membrane dissection were significantly more common in group 3 than in group $2\left(P<0.001, \chi^{2}\right.$ test). Incidences of peripheral breaks and oral dialysis did not differ significantly among the three groups $(P=0.359$ and $P=0.087$, respectively, $m x n \chi^{2}$ test).

Table I Incidence of each type of iatrogenic break

\begin{tabular}{lllll}
\hline latrogenic break & $\begin{array}{l}\text { Group I } \\
(\mathbf{n}=\mathbf{2 5 9})\end{array}$ & $\begin{array}{l}\text { Group 2 } \\
(\mathbf{n}=\mathbf{3} \text { I8) }\end{array}$ & $\begin{array}{l}\text { Group 3 } \\
(\mathbf{n}=183)\end{array}$ & P-value \\
\hline $\begin{array}{l}\text { During membrane } \\
\text { dissection }\end{array}$ & No dissection & $67(21.0)$ & $9 \mathrm{II}(49.7)$ & $<0.00 \mathrm{I}^{*}$ \\
$\begin{array}{l}\text { Peripheral } \\
\text { Oral dialysis }\end{array}$ & $2 \mathrm{I}(8.1)$ & $19(6.0)$ & $17(9.3)$ & $0.359^{\dagger}$ \\
\hline
\end{tabular}

Notes: Group I, vitreous hemorrhage only; group 2, fibrovascular membranes requiring treatment without traction retinal detachment; group 3, fibrovascular membrane with traction retinal detachments. Eyes (\%). Some eyes showed multiple types of breaks. ${ }^{\dagger} m x n \chi^{2}$ test; ${ }^{*} \chi^{2}$ test. 


\section{Postoperative complications}

\section{All cases}

Evaluation of postoperative complications in all 760 eyes showed rebleeding in 3.6\%, neovascularization at the sclerotomy site in $1.3 \%$, retinal detachment due to reproliferation in $2.8 \%$, and neovascular glaucoma in $3.9 \%$.

\section{According to group}

The incidence of rebleeding and that of neovascular glaucoma were higher in group 3 than in group $1(P=0.013$ and $P=0.008$, respectively, Bonferroni method; Table 2). Furthermore, the incidence of neovascularization at the sclerotomy site and that of retinal detachment due to reproliferation was higher in group 3 than in group $2(P=0.007$ and $P=0.001$, respectively, Bonferroni method, $\chi^{2}$ test).

\section{Associations between visual outcomes after rebleeding and neovascularization at sclerotomy site}

Vitreous rebleeding was observed in 27 eyes, ie, 10 eyes with and 17 eyes without neovascularization at the sclerotomy site. Final visual acuity was $<0.1$ in all 10 eyes showing neovascularization at the sclerotomy site, and in $41.2 \%$ of the 17 eyes without this complication. The final visual acuity was poorer in the presence of neovascularization at the sclerotomy site $(P=0.002$, Fisher's exact probability test). Neovascular glaucoma developed in $80.0 \%$ of the 10 eyes showing neovascularization at the sclerotomy site and $35.3 \%$ of the 17 eyes without this complication, being significantly more frequent in the presence of neovascularization $(P=0.031$, Fisher's exact probability test).

\section{Associations between visual outcomes after retinal detachment due to reproliferation and neovascular glaucoma}

Retinal detachment due to reproliferation occurred in 21 eyes. Reoperation for retinal detachment due to reproliferation was performed 1-3 (mean 1.4) times, and retinal reattachment

Table 2 Postoperative complications

\begin{tabular}{|c|c|c|c|c|}
\hline & $\begin{array}{l}\text { Group I } \\
(n=259)\end{array}$ & $\begin{array}{l}\text { Group } 2 \\
(n=3 \mid 8)\end{array}$ & $\begin{array}{l}\text { Group } 3 \\
(n=183)\end{array}$ & $P$-value \\
\hline Vitreous rebleeding & $5(1.9)$ & $10(3.1)$ & $12(6.6)$ & $0.03^{\dagger}$ \\
\hline $\begin{array}{l}\text { Neovascularization } \\
\text { at the sclerotomy site }\end{array}$ & $3(1.2)$ & $I(0.3)$ & $6(3.3)$ & $0.019^{\dagger}$ \\
\hline $\begin{array}{l}\text { Retinal detachment } \\
\text { due to reproliferation }\end{array}$ & $0(0)$ & $6(1.9)$ & I5 (8.2) & $<0.00 I^{*}$ \\
\hline Neovascular glaucoma & $6(2.3)$ & $10(3.1)$ & $14(7.7)$ & $0.0 \mathrm{II}^{\dagger}$ \\
\hline
\end{tabular}

was achieved in only $38 \%$ of these eyes. Final visual acuity was $<0.1$ in $25 \%$ of the eight eyes showing retinal reattachment, but was $<0.1$ in all 13 eyes without retinal reattachment, with poorer visual acuity in the latter $(P<0.001$, Fisher's exact probability test). None of the eight eyes showing retinal reattachment developed neovascular glaucoma, but this complication did occur in $38.5 \%$ of the 13 eyes without retinal reattachment. However, the incidences did not differ significantly between the two groups $(P=0.063$, Fisher's exact probability test).

\section{Associations between iatrogenic breaks and postoperative complications}

Associations between iatrogenic breaks and postoperative complications were evaluated by logistic regression analysis. Breaks during membrane dissection were significantly associated with vitreous rebleeding $(P=0.019)$, retinal detachment due to reproliferation $(P<0.001)$, and neovascular glaucoma $(P=0.048$; Table 3$)$. Peripheral breaks were not associated with postoperative complications, while oral dialysis was associated with rebleeding $(P=0.001)$.

\section{Discussion}

Vitreous surgery for proliferative diabetic retinopathy is associated with severe intraoperative and postoperative complications, which might cause worsening of visual outcomes. ${ }^{1}$ Iatrogenic retinal breaks and intraocular bleeding are major intraoperative complications. ${ }^{1}$ However, iatrogenic breaks include breaks occurring by different mechanisms, such as breaks at the posterior pole during fibrovascular membrane dissection, those in the peripheral retina during posterior vitreous detachment induction or thorough dissection of the peripheral vitreous, and oral dialysis associated with instrument insertion and removal, and their influences on outcomes would presumably differ. To our knowledge, there has been only one previous study in which iatrogenic retinal breaks were classified according to the mechanisms of development. ${ }^{2}$ However, the relationships between iatrogenic breaks and postoperative complications were not evaluated.

Herein, we clarified the associations between iatrogenic breaks and major postoperative complications in the largest series of patients undergoing 20-gauge vitrectomy for proliferative diabetic retinopathy published to date. These evaluations may provide basic data allowing comparison between 20 -gauge vitrectomy and microincision vitreous surgery for proliferative diabetic retinopathy.

Among postoperative complications, vitreous rebleeding consistently develops at a predictable rate after vitreous 
Table 3 latrogenic breaks and postoperative complications

\begin{tabular}{|c|c|c|c|c|}
\hline & VH & NV & RD & NVG \\
\hline \multicolumn{5}{|c|}{ Breaks during membrane dissection } \\
\hline OR & $2.6(1.2-5.7)$ & I.7 (0.42-7.3) & $8.0(3.3-19.4)$ & $2.2(1.0-4.8)$ \\
\hline$P$-value & 0.019 & 0.444 & $<0.00 \mathrm{I}$ & 0.048 \\
\hline \multicolumn{5}{|c|}{ Peripheral breaks } \\
\hline OR & $1.3(0.29-5.7)$ & $3.9(0.77-20.1)$ & $1.0(0.138 .1)$ & I.I (0.25-4.8) \\
\hline$P$-value & 0.737 & 0.100 & 0.986 & 0.910 \\
\hline \multicolumn{5}{|c|}{ Oral dialysis } \\
\hline OR & $8.0(2.3-27.5)$ & $5.7(0.64-50.7)$ & $3.0(0.59-15.0)$ & $3.0(0.64-14.4)$ \\
\hline$P$-value & 0.001 & 0.200 & 0.188 & 0.162 \\
\hline
\end{tabular}

Abbreviations: $\mathrm{VH}$, vitreous rebleeding; NV, neovascularization at sclerotomy site; RD, retinal detachment due to reproliferation; NVG, neovascular glaucoma; OR, odds ratio ( $95 \%$ confidence interval).

surgery for proliferative diabetic retinopathy despite its minimal influences on visual outcomes. ${ }^{1}$ In contrast, neovascularization at the sclerotomy site, retinal detachment due to reproliferation, and neovascular glaucoma are considered to carry poor prognoses..$^{1,3-5}$

In this study, certain iatrogenic breaks occurred in about $30 \%$ of all cases. Studies in more than 100 eyes have shown the incidence of iatrogenic breaks in 20-gauge surgery to range from $33 \%$ to $41 \%{ }^{3,6,7}$ Breaks developed in about $30 \%$ of our cases during fibrovascular membrane dissection. The incidence was significantly higher in those with traction retinal detachment. This difference might be attributable to traction retinal detachment inducing atrophy and fragility of the detached retina, thereby allowing the development of iatrogenic retinal breaks.

The incidence of peripheral breaks developing during induction of posterior vitreous detachment or peripheral vitreous dissection, and that of oral dialysis related to the sclerotomy sites, did not differ significantly among the three groups. The incidence of peripheral breaks during the induction of posterior vitreous detachment or peripheral vitreous dissection is reportedly $6 \%,{ }^{2}$ while those with oral dialysis have been shown to be $8 \%{ }^{2}$ and $6 \% .{ }^{8}$ Concerning postoperative complications, the incidence of each complication was highest in group 3, and the incidences of retinal detachment due to reproliferation and neovascular glaucoma were about $8 \%$ each.

The incidence rates of each of these complications were similar to those obtained by Oda et $a l,{ }^{3}$ who reported the highest incidence of postoperative complications in the traction retinal detachment group and that incidences of reproliferation and neovascular glaucoma each exceeded $10 \%$. Therefore, cases with fibrovascular membranes should be closely followed up. If progressive membrane contraction likely to cause traction retinal detachment is detected, surgical intervention should be considered. Evaluating the association between iatrogenic breaks and postoperative complications may provide useful information for the management of patients who have already developed this detachment. Oda et $\mathrm{al}^{3}$ evaluated the association between iatrogenic breaks and postoperative complications, and the final visual acuity was $<0.1$ in $30 \%$ of cases developing iatrogenic retinal breaks, and the odds ratio as a risk factor for final visual acuity $<0.1$ was 1.9 . Yorston et $\mathrm{al}^{7}$ reported iatrogenic breaks to be a risk factor for worsening of postoperative visual acuity. However, in their study, the types of iatrogenic breaks were not evaluated. In the present study, retinal breaks during fibrovascular membrane dissection were significantly associated with postoperative rebleeding, retinal detachment due to reproliferation, and neovascular glaucoma. Furthermore, there was a significant association between oral dialysis and rebleeding. Therefore, if the incidences of iatrogenic breaks during membrane dissection and oral dialysis can be lowered, the incidences of these postoperative complications can likely be reduced as well.

Despite providing basic data on iatrogenic retinal breaks during 20-gauge vitrectomy for proliferative diabetic retinopathy in the largest published patient series to date, this study is limited by being retrospective and non-randomized. A prospective, randomized clinical trial is needed for comparison between 20-gauge vitrectomy and micro-incision vitreous surgery for proliferative diabetic retinopathy.

\section{Disclosure}

The authors report no conflicts of interest in this work.

\section{References}

1. Eliott D, Lee MS, Abrams GW. Proliferative diabetic retinopathy: principles and techniques of surgical treatment. In: Ryan SJ, editor. Retina, 4th ed. St Louis, MO: Mosby; 2006.

2. Issa SA, Connor A, Habib M, Steel DHW. Comparison of retinal breaks observed during 23 gauge transconjunctival vitrectomy versus conventional 20 gauge surgery for proliferative diabetic retinopathy. Clin Ophthalmol. 2011;20:109-114. 
3. Oda H, Konno K, Mitsui K, Kawamata E, Hiraoka T, Miki D. Recent outcome of vitreous surgery for diabetic retinopathy. Nippon Ganka Gakkai Zasshi. 2005;109:603-612. Japanese.

4. Charles S, Calzada J, Wood B. Diabetic retinopathy. In: Charles S, editor. Vitreous Microsurgery, 5th ed. Philadelphia, PA: Wolters Kluwer/ Lippincott Williams \& Wilkins; 2011.

5. Sawa H, Ikeda T, Matsumoto Y, Niiya A, Kinoshita S. Neovascularization from scleral wound as cause of vitreous rebleeding after vitrectomy for proliferative diabetic retinopathy. Jpn J Ophthalmol. 2000;44: $154-160$.
6. Higuchi A, Yamada H, Kawai E, et al. Vitrectomy for proliferative diabetic retinopathy. Nippon Ganka Gakkai Zasshi. 2005;109:134-141. Japanese.

7. Yorston D, Wickham L, Benson S, Bunce C, Sheard R, Charteris D. Predictive clinical features and outcomes of vitrectomy for proliferative diabetic retinopathy. Br J Ophthalmol. 2008;92:365-368.

8. Oyakawa RT, Schachat AP, Michels RG, Rice TA. Complications of vitreous surgery for diabetic retinopathy. I. Intraoperative complications. Ophthalmology. 1983;90:517-521.
Clinical Ophthalmology

\section{Publish your work in this journal}

Clinical Ophthalmology is an international, peer-reviewed journal covering all subspecialties within ophthalmology. Key topics include: Optometry; Visual science; Pharmacology and drug therapy in eye diseases; Basic Sciences; Primary and Secondary eye care; Patien Safety and Quality of Care Improvements. This journal is indexed on

Submit your manuscript here: http://www.dovepress.com/clinical-ophthalmology-journal

\section{Dovepress}

PubMed Central and CAS, and is the official journal of The Society of Clinical Ophthalmology (SCO). The manuscript management system is completely online and includes a very quick and fair peer-review system, which is all easy to use. Visit http://www.dovepress.com/ testimonials.php to read real quotes from published authors. 